Strength recovery of concr ete exposed to

freezing-thawing by self-heal ing of

cementitious material s using synt het ic fi ber

\begin{tabular}{|l|l|}
\hline 著者 & $\begin{array}{l}\text { CHO Heesup, I NOUE Nasum , SENGOKU Ri sa, } \\
\text { CHANG Young-Cheol }\end{array}$ \\
\hline $\begin{array}{l}\text { j our nal or } \\
\text { publ i cat i on ti t l e }\end{array}$ & Advanced Nat er i al s Let ter s \\
\hline vol une & 8 \\
\hline number & 10 \\
\hline page r ange & 993 998 \\
\hline year & $2017-10$ \\
\hline URL & ht t p: //hdl . handl e. net /10258/00009508 \\
\hline
\end{tabular}




\title{
Strength recovery of concrete exposed to freezing-thawing by self-healing of cementitious materials using synthetic fiber
}

\author{
Heesup Choi ${ }^{1 *}$, Masumi Inoue ${ }^{1}$, Risa Sengoku', Hyeonggil Choi ${ }^{2}$ \\ ${ }^{1}$ Department of Civil and Environmental Engineering, Kitami Institute of Technology, Hokkaido, 090-8507, Japan \\ ${ }^{2}$ Faculty of Environmental Technology, Muroran Institute of Technology, Hokkaido, 090-8585, Japan \\ "Corresponding author: E-mail: hs-choi@ mail.kitami-it.ac.jp
}

Received: 23 January 2017, Revised: 18 February 2017 and Accepted: 09 April 2017

DOI: $10.5185 /$ amlett.2017.1635

www.vbripress.com/aml

\begin{abstract}
In this study, it is possible to disperse effectively cracked using synthetic fiber, an examination of the most suitable selfhealing conditions was performed on the above crack width $0.1 \mathrm{~mm}$. As a result, effective crack dispersion using polyvinyl alcohol (PVA) fibers with polar $\mathrm{OH}^{-}$groups, as well as improved self-healing for cracks that are larger than $0.1 \mathrm{~mm}$ in width, posing concerns of $\mathrm{CO}_{2}$ gas and $\mathrm{Cl}^{-}$penetration, were observed. Also, $\mathrm{CO}_{3}{ }^{2-}$ reacts with $\mathrm{Ca}^{2+}$ in the concrete crack, resulting in the precipitation of a carbonate compound, $\mathrm{CaCO}_{3}$. Based on this, it is deemed possible for the recovery of effective water tightness and strength recovery through effective freezing-thawing resistance to be made from cracks that are larger than 0.1 $\mathrm{mm}$ in width. In addition, it was determined that, as for the most suitable self-healing conditions in the inside and surface of the cracks, calcium hydroxide $\left(\mathrm{Ca}(\mathrm{OH})_{2}\right)$ solution with $\mathrm{CO}_{2}$ micro-bubble was more effective in promoting the self-healing capability than water with $\mathrm{CO}_{2}$ micro-bubble. Copyright $\odot 2017$ VBRI Press.
\end{abstract}

Keywords: Freeze-thaw, micro-crack, PVA fiber, $\mathrm{CO}_{2}$ micro-bubble, self-healing, water tightness, strength recovery.

\section{Introduction}

Concrete and cementitious building materials are essential in civil engineering for constructing buildings for the modern society. It is thought that in the near future, development of construction materials that can completely replace concrete will become exceptionally challenging. As concrete as a material has a lower tensile strength than compressive strength, the occurrence of cracks in concrete structures is inevitable. In Japan, as long as these cracks are smaller than the acceptable crack width, they are not considered as a major problem with respect to structural durability [1]. However, even if fine cracks do not immediately reduce the safety performance of a structure, degradation factors such as $\mathrm{CO}_{2}$ and $\mathrm{Cl}^{-}$can permeate into concrete through these fine cracks, and as these accumulate, water permeability, which is an evaluation index for the evaluation of durability, also increases [2]. As these deterioration factors continue to permeate deeper, the cracks widen, the degradation of concrete accelerates, and the possibility of the concrete structure being irreparably damaged rises. Therefore, it is essential to make an effort such that the occurrence of fine cracks in concrete structures can be prevented in its initial stages. In an environment where there is moisture, some of the cracks present in concrete can undergo a 'fillingup' or clogging phenomenon causing self-healing, particularly when their width is sufficiently small. This is caused by rehydration reactions and the depositing of substances such as $\mathrm{CaCO}_{3}[3]$. The latter repair mechanism involves the reaction between $\mathrm{Ca}^{2+}$ present in concrete and $\mathrm{CO}_{3}{ }^{2-}$ dissolved in water to form $\mathrm{CaCO}_{3}$, which helps in healing of the cracks [3]. The calcite crystal reactions are shown in Eqs.(1)-(3):

$$
\begin{aligned}
& \mathrm{H}_{2} \mathrm{O}+\mathrm{CO}_{2} \Leftrightarrow \mathrm{H}_{2} \mathrm{CO}_{3} \Leftrightarrow \mathrm{H}^{+}+\mathrm{HCO}_{3} \Leftrightarrow 2 \mathrm{H}^{+}+\mathrm{CO}_{3}{ }^{2-} \\
& \mathrm{Ca}^{2+}+\mathrm{CO}_{3}{ }^{2-} \Leftrightarrow \mathrm{CaCO}_{3}\left\{\mathrm{pH}_{\text {water }}>8\right\} \\
& \mathrm{Ca}^{2+}+\mathrm{HCO}_{3}{ }^{-} \Leftrightarrow \mathrm{CaCO}_{3}+\mathrm{H}^{+}\left\{7.5<\mathrm{pH}_{\text {water }}<8\right\}
\end{aligned}
$$

As a result of this self-healing phenomenon, the formation of cracks in concrete and the permeation of $\mathrm{Cl}^{-}$ and $\mathrm{CO}_{2}$ can be delayed, which reduces a certain amount of the water permeability that results from the occurrence and development of these cracks [4]. Furthermore, it is possible to recover some of the dynamic modulus of elasticity of concrete, which had deteriorated because of freezing and thawing. This implies that the strength of concrete may be recovered to a certain extent [5]. Therefore, if cracks can be repaired autonomously through self-healing, this process may significantly contribute to reducing the burden of maintaining and prolonging the lifespan of concrete structures. Owing to this phenomenon, the early stages of deterioration, i.e. 
when cracks are formed, can be checked. This can lead to an increase in the durability of concrete structures. In existing research pertaining to this self-healing phenomenon, it has been reported that standard concrete cracks of up to $0.1 \mathrm{~mm}$ in size can recover through self-healing [6]. Additionally, the cracks occurring in concrete can be dispersed by mixing synthetic fibers such as polyvinyl alcohol (PVA) and polypropylene (PE) into cementitious material. This method has been proposed as a means to efficiently promote self-healing by reducing the width of the cracks that have formed in concrete [7]. In particular, it has been shown that the use of PVA fibers, containing $\mathrm{OH}^{-}$polar groups, results in an improved self-healing performance [8].

In this research, we conducted experiments pertaining to cementitious repair materials that are used for the recovery and reinforcement of the deteriorated concrete structures. We also investigated the use of synthetic fibers for effectively dispersing the cracks that are generated and expanded by freezing. In self-healing cracks that were $0.1 \mathrm{~mm}$ or larger, the penetration of degradation factors was suppressed in the portion containing recovery materials (Experiment 1). We also evaluated the recovery of strength of cementitious materials by self-healing that had been frozen and thawed (Experiment 2).

Table 1. Mixture proportions of the mortar.

\begin{tabular}{lllll}
\hline Type & $\begin{array}{l}\text { S/C } \\
(\text { Wt. \%) }\end{array}$ & W/C (Wt.\%) & SP/C (Wt.\%) $) \begin{array}{l}\text { Fiber } \\
\text { (vol.\%) }\end{array}$ \\
\hline PVA & & & & 1.2 \\
PP & 0.4 & 0.3 & 0.25 & 1.5 \\
\hline
\end{tabular}

\section{Experimental}

\section{Materials}

As the experimental materials in this study, Portland cement (C, density: $3.16 \mathrm{~g} / \mathrm{cm}^{3}$, mean diameter: $\left.10 \mu \mathrm{m}\right)$, quartz sand as the fine aggregate $(\mathrm{S}$, surface-dry density: $2.61 \mathrm{~g} / \mathrm{cm}^{3}$, mean diameter: $180 \mu \mathrm{m}$ ), and a highperformance water reducing agent as an admixture (SP, density: $1.05 \mathrm{~g} / \mathrm{cm}^{3}$, main constituent: polycarboxylatebased superplasticizer) were used. As for the synthetic fibers, PVA (fiber diameter: $100 \mu \mathrm{m}$, fiber length: $12 \mathrm{~mm}$, density: $1.3 \mathrm{~g} / \mathrm{cm}^{3}$ ) and polypropylene (PP) (fiber diameter: $300 \mu \mathrm{m}$, fiber length: $12 \mathrm{~mm}$, density: 0.91 $\mathrm{g} / \mathrm{cm}^{3}$ ) were used. The mixture proportions of the mortar are summarized in Table $\mathbf{1}$. The properties of the employed fibers are presented in Table 2. The characteristic part of the chemical components of the employed synthetic fibers consists of polar groups indicated by the circle in Fig. 1. PVA has the highest polarity strength owing to the $\mathrm{OH}$ radical, whereas PP has no polarity strength.

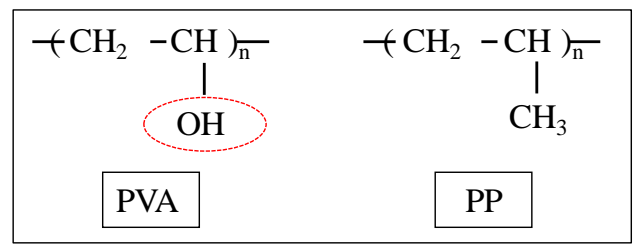

Fig. 1. Characteristic part of the chemical components of each fiber.

Evaluation of water tightness by fiber type and self-healing conditions (Experiment 1)

\section{Experimental outline}

In this experiment, the composite self-healing performance of the cementitious materials having PVA fibers incorporated into them was studied. Self-healing was observed in cracks having a width of $0.3 \mathrm{~mm}$, which were introduced into the material through tensile loading. By using the coefficient of water permeability, selfhealing performance was evaluated and optimal selfhealing methods were also studied. Furthermore, the presence of self-healing substances was confirmed using Raman spectroscopic analysis.

\section{Experiment and methods}

In this TEST, the dimensions of the specimens were $85 \times 80 \times 30 \mathrm{~mm}(\mathrm{~L} \times \mathrm{B} \times \mathrm{H})$. Two specimens were fabricated for each series. After mixing the mortar with the fibers, water curing was performed in a tank at $20^{\circ} \mathrm{C}$ for 28 days. A universal testing machine (UTM) was used to apply a tensile load at a speed of $0.2 \mathrm{~mm} / \mathrm{min}$, and the crack width was adjusted so that the displacement of the PI displacement transducer would be about $0.3 \mathrm{~mm}$. Fig. 2(a) and (b) show the mimetic diagram of the specimens, used in crack introduction, and the tensile load test.

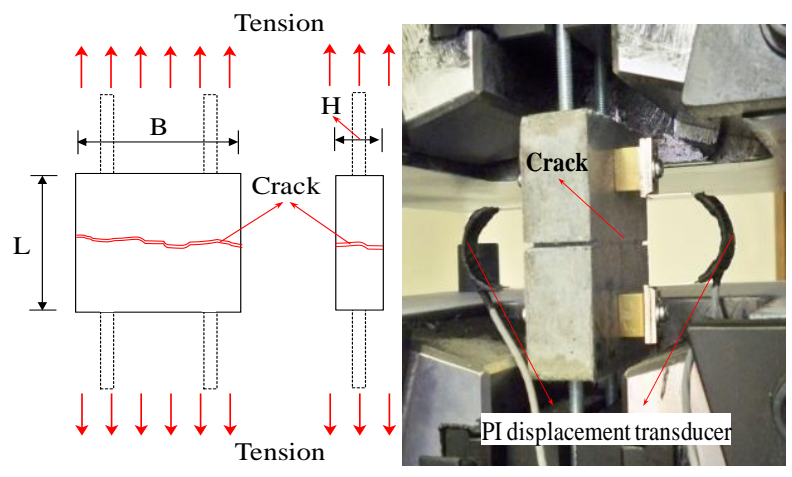

(a) Geometry of the specimen(b) Direction of the load during the tensile test

Fig. 2. Specimen overview.

Table 2. Properties of employed fibers.

\begin{tabular}{llllll}
\hline Type & Type of Fiber & Density $\left(\mathbf{g} / \mathbf{c m}^{\mathbf{3}}\right)$ & $\begin{array}{l}\text { Tensile Strength } \\
(\mathbf{G P a})\end{array}$ & Length $(\mathbf{m m})$ & Diameter $(\boldsymbol{\mu m})$ \\
\hline PVA & Polyvinyl alcohol & 1.30 & 1.6 & 12 & 100 \\
PP & Polypropylene & 0.91 & 0.7 & 12 & 300 \\
\hline
\end{tabular}


Table 3 summarizes the experimental procedure. In the first step (A), the coefficient of water permeability (K) was measured after introducing cracks in a tensile loading test. In the next step, $\mathrm{K}$ was measured after the test materials underwent self-healing (Step B). Self-healing performance was evaluated using both tap water and an aqueous solution (solubility: $0.82 \mathrm{~g} / \mathrm{L}$ ) of calcium hydroxide (hereafter $\mathrm{Ca}(\mathrm{OH})_{2}$ ), in a water tank that had a provision for introducing $\mathrm{CO}_{2}$ micro-bubbles to each specimen, and for soaking the test materials in water $\left(20^{\circ} \mathrm{C}\right)$. It has been reported that self-healing can be promoted by using saturated $\mathrm{Ca}(\mathrm{OH})_{2}$ aqueous solution as a source for calcium ions $\left(\mathrm{Ca}^{2+}\right)[9]$, and $\mathrm{CO}_{2}$ micro-bubbles also promote recovery owing to the increased supply of carbonate ions $\left(\mathrm{CO}_{3}{ }^{2-}\right)$ during this process[10]. These methods were also adopted in this study to maximize self-healing. The self-healing period was set at 7 days with the temperature of water as $20^{\circ} \mathrm{C}$, and the $\mathrm{pH}$ concentration was adjusted as given in Table 3. In Step $C$, the specimens that had previously undergone self-healing in Step B were subjected to repeated freezing and thawing, and cracks resulting from freezing damage were introduced. The freeze-thaw test was completed after 100 cycles according to JIS A 1148 and ASTM C 666, and the coefficient of water permeability was subsequently measured. Finally, in Step $\mathrm{D}$, self-healing was performed using the same methods as in Step B, and the coefficient of water permeability was determined again. Next, to confirm the crystalline components of the substances resulting from the selfhealing process, Raman spectroscopic analysis was performed on the cracked portion to which the selfhealing substances had attached (Step D). The apparatus used in the water permeability tests in this study is shown in Fig. 3[11].
Evaluation of strength recovery from self-healing of cementitious materials that underwent freeze-thaw (experiment 2)

\section{Experimental outline}

In this experiment, the strength recovery of cementitious materials that underwent self-healing by the introduction of synthetic fibers after freeze-thaw damage was evaluated. The optimal self-healing method was selected based on the results of Experiment 1. The effectiveness of the strength recovery process was evaluated based on the change in the relative dynamic modulus of elasticity and flexural strength according to the time variation. In addition, the presence of self-healing substances on the surface of the fibers was confirmed by SEM (scanning electron microscopy) imaging.

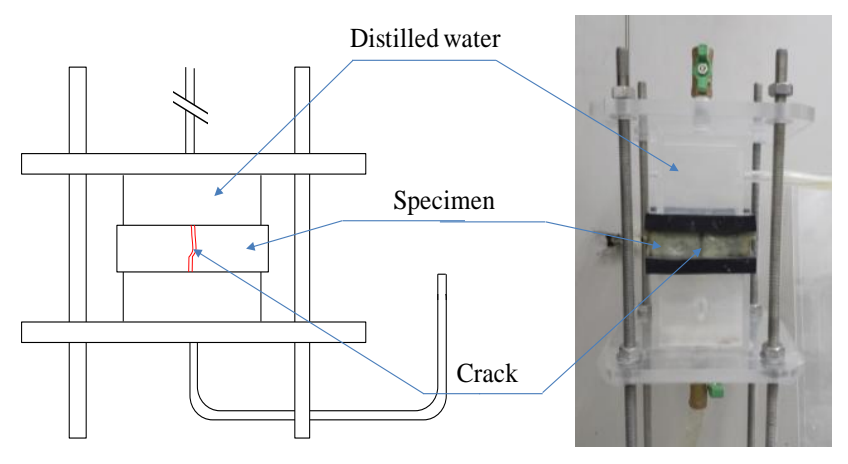

Fig. 3. Apparatus used in the water permeability tests [11].

\section{Experiment and methods}

The dimensions of the specimens used for testing the relative modulus of elasticity and the bending test were $100 \times 100 \times 400 \mathrm{~mm}$ (B x H x L) and 40 x 40 x $160 \mathrm{~mm}$

Table 3. Experimental procedure (Experiment 1)

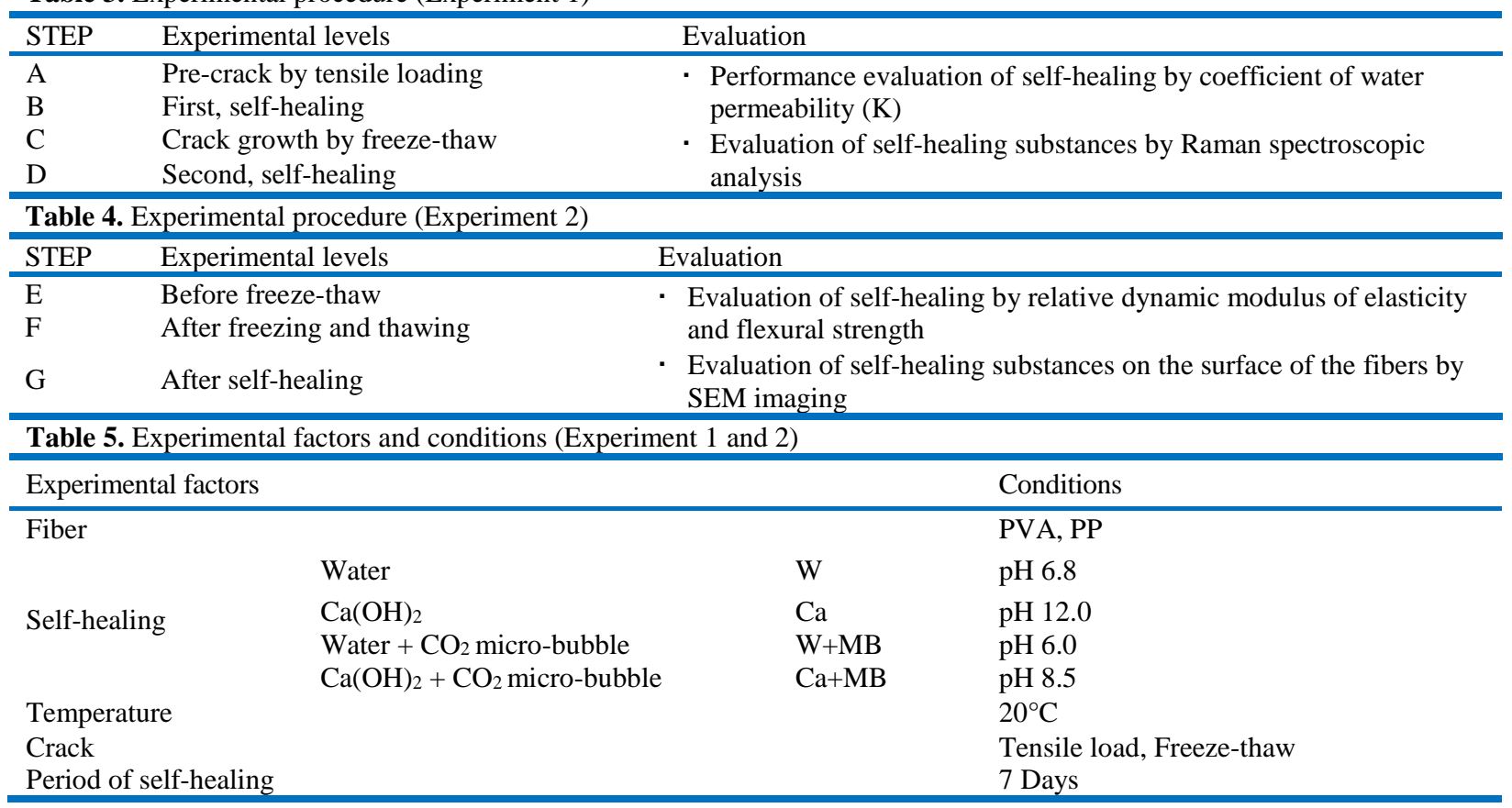


(B $x \mathrm{H} \times \mathrm{L}$ ). They were cured in the same manner as used in Experiment 1, and cracks were introduced by repeated freezing and thawing.

Table 4 summarizes the experimental procedure. The experimental method employed was Method A of JIS A 1148, "Method of Freezing and Thawing Concrete". The relative dynamic modulus of elasticity and flexural strength were determined for each specimen before freeze-thaw (Step E), after 300 cycles of freeze-thaw (Step F), and after 7 days of self-healing (Step G). The self-healing method used in each case was terminated after 300 cycles of freeze-thaw, based on the results of Experiment 1 . In order to increase the supply of calcium $\left(\mathrm{Ca}^{2+}\right)$ and carbonate $\left(\mathrm{CO}_{3}{ }^{2-}\right)$ ions, the experiment was conducted with two cases $(\mathrm{W}+\mathrm{MB}$ and $\mathrm{Ca}+\mathrm{MB})$ by micro $\mathrm{CO}_{2}$ bubbles added and a $\mathrm{Ca}(\mathrm{OH})_{2}$ solution. Subsequently, SEM imaging was done to confirm the presence of substances, which had formed owing to presence of PVA fibers in the cracked part of the specimen that had been subjected to freeze-thaw (Step G). Table 5 summarizes the experimental conditions of Experiments 1 and 2.

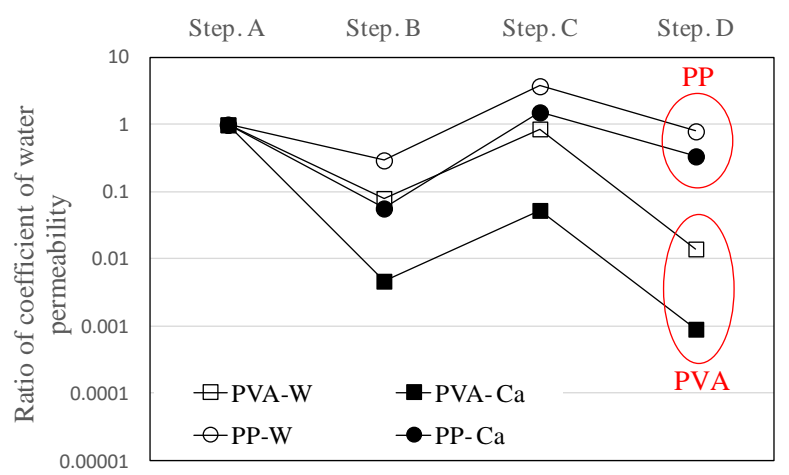

Fig. 4. $\mathrm{W} \cdot \mathrm{Ca}$ case (fiber $1.2 \%$ ).

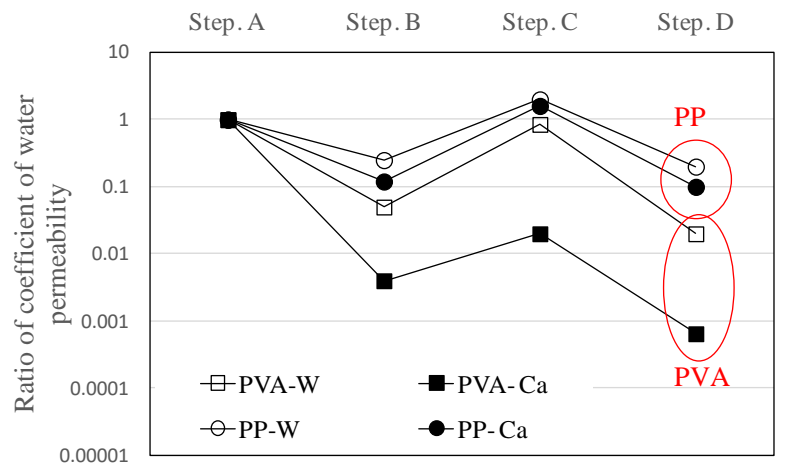

Fig. 5. W $\bullet$ Ca case (fiber 1.5\%).

\section{Results and discussion}

Evaluation of water tightness by fiber type and selfhealing conditions (experiment 1)

Figs. 4-7 show the water permeability coefficient ratio for each fiber series, calculated from the coefficient of water permeability as determined in Step A. In the case of selfhealing using water and $\mathrm{Ca}(\mathrm{OH})_{2}$ solution, i.e. Step D, PVA showed approximately 60-400 times more recovery of watertightness than PP (Figs 4 and 5). Additionally, through the use of $\mathrm{Ca}(\mathrm{OH})_{2}$ solution, the specimen showed a greater tendency toward self-healing compared to when tap water was used [9]. Similarly, when micro $\mathrm{CO}_{2}$ bubbles were added to water and $\mathrm{Ca}(\mathrm{OH})_{2}$ solution, PVA showed approximately 100-400 times more recovery of watertightness than PP. Furthermore, it was observed that the micro $\mathrm{CO}_{2}$ bubbles promoted self-healing as the dispersion of fibers is better compared to the case where they were not present. This is due to the increase in the concentration of calcium $\left(\mathrm{Ca}^{2+}\right)$ and carbonate ions $\left(\mathrm{CO}_{3}{ }^{2-}\right)$ in the $\mathrm{Ca}(\mathrm{OH})_{2}$ solution[10]. From these observations, it can be concluded that PVA always showed a better self-healing performance than PP, regardless of the amount of fiber that was mixed in the specimen. In particular, PVA with $\mathrm{OH}^{-}$groups was very effective in its self-healing performance. Moreover, $\mathrm{Ca}+$ MB demonstrated an improved self-healing performance compared to $\mathrm{W}+\mathrm{MB}$. Based on these experimental results, the use of PVA fibers along with $\mathrm{Ca}(\mathrm{OH})_{2}$ solution and $\mathrm{CO}_{2}$ micro-bubbles was judged to provide the most effective conditions for encouraging the production of self-healing substances for cracks with a width of $0.3 \mathrm{~mm}$.

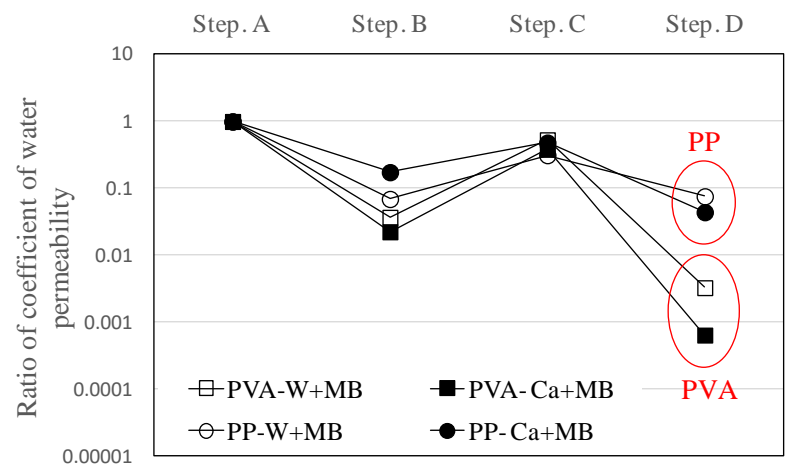

Fig. 6. $\mathrm{W}+\mathrm{MB} \cdot \mathrm{Ca}+\mathrm{MB}$ case (fiber $1.2 \%)$.

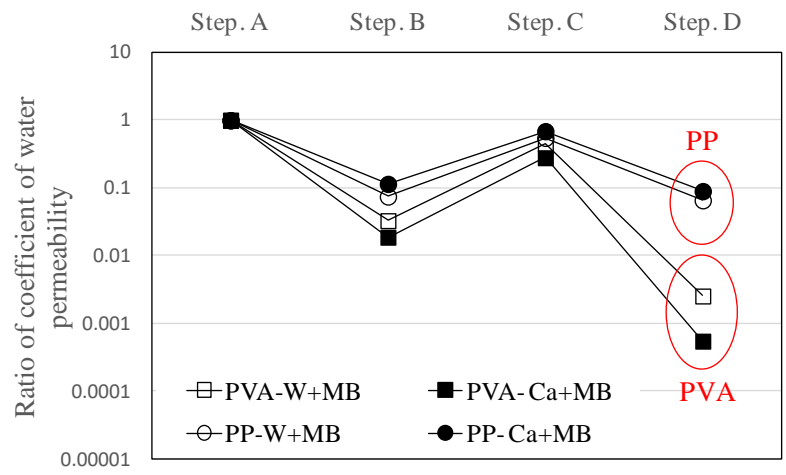

Fig. 7. $\mathrm{W}+\mathrm{MB} \cdot \mathrm{Ca}+\mathrm{MB}$ case (fiber $1.5 \%)$.

To confirm the nature of the crystalline components of the substances resulting from self-healing, Raman spectroscopic analysis was performed. The self-healing substances in the crack of PVA-Ca $+\mathrm{MB}$ (Fiber 1.5\%, Step D) were obtained from the test specimen and irradiated with a laser, such that the positions of the wavelength peaks could be compared. Fig. 8(a) is a 
photograph of the apparatus used, and 8(b) shows the results obtained from the Raman spectroscopic analysis. The wavelength of the cracked portion clearly matched with the wavelength peak in the spectrum of $\mathrm{CaCO}_{3}$ powder. Thus, it was confirmed that the substances constituting the white substances that are formed after the self-healing process were predominantly $\mathrm{CaCO}_{3}$.

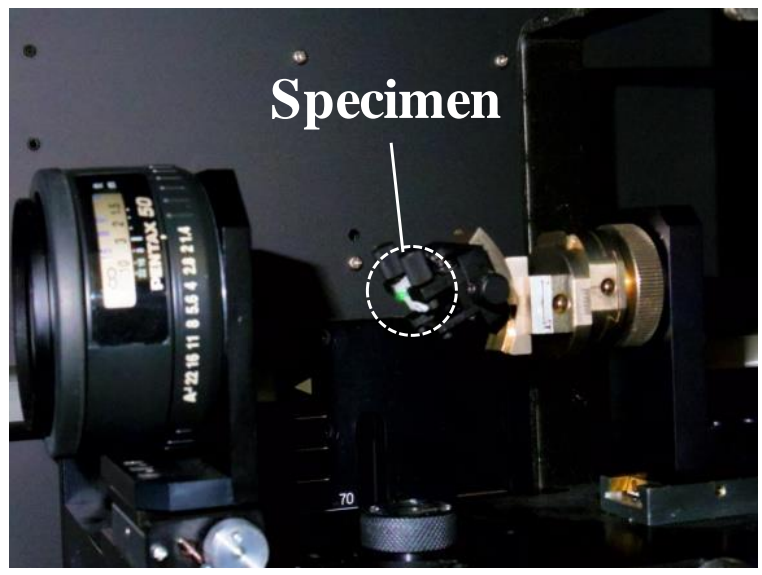

(a) Raman spectroscopy

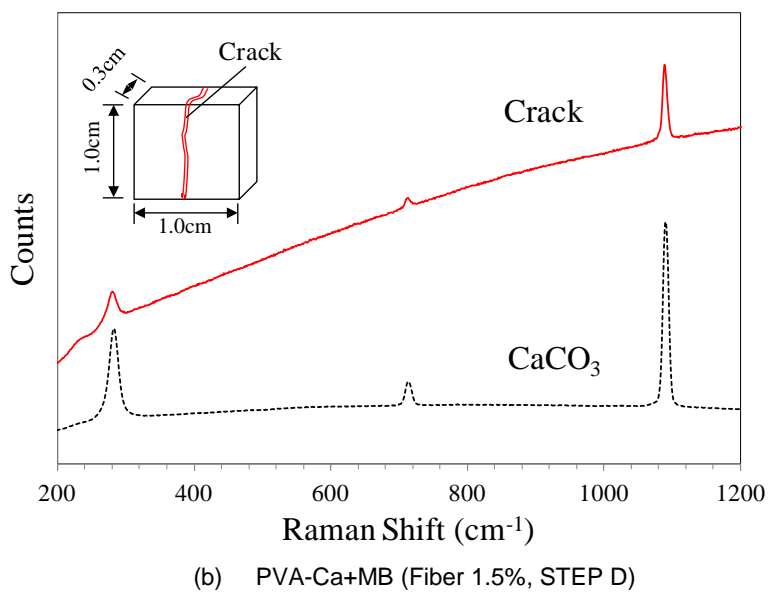

Fig. 8. Raman spectroscopy analysis.

Evaluation of strength recovery from self-healing of cementitious materials that underwent freeze-thaw (experiment 2)

Figs 9-12 show the relative dynamic modulus of elasticity and flexural strength ratio for each fiber series. In Fig. 9 and Fig. 10, from the time before (Step E) till after (Step F) the freeze-thaw, degradation of the relative dynamic modulus of elasticity was a result of the freeze-thaw process. In the case of $\mathrm{W}+\mathrm{MB}$ (Fig. 9), after 300 freezethaw cycles (Step F) and 7 days of self-healing (Step G), there was hardly any change in the relative dynamic modulus of elasticity in the OPC and PP series. However, the relative dynamic modulus of elasticity tended to recover by ca. $10 \%$ for the PVA series, going from $70 \%$ in Step F to $80 \%$ in Step G. In the $\mathrm{Ca}+\mathrm{MB}$ case (Fig. 10), case (Fig. 10), although the relative dynamic modulus of elasticity for the OPC and PP series increased only slightly from Step F to Step G, there was an increase of ca. $8-10 \%$ for the PVA series. Fig. 11 and Fig. 12 show the results of the calculated flexural strength ratio based on the flexural strength before the freeze-thaw (Step E) for each fiber series. In the $\mathrm{W}+\mathrm{MB}$ case (shown in Fig. 11), after 300 cycles of freeze-thaw (Step F) and 7 days of self-healing (Step G), the flexural strength of the OPC and PP series recovered ca. 20-25\%, while the PVA series showed a tendency to recover more, ca. $35 \%$. Furthermore, in the $\mathrm{Ca}+\mathrm{MB}$ case (Fig. 12) from Step $\mathrm{F}$ to Step G, the flexural strength of the OPC and PP series recovered by about $25 \%$, and the PVA series showed a tendency to recover its strength by nearly $50 \%$. From the results of the relative dynamic modulus of elasticity and the flexural strength ratio, it can be concluded that the PVA series with $\mathrm{OH}^{-}$groups demonstrates improved strength and effective self-healing when compared to the OPC and PP series. Furthermore, it was determined that the self-healing performance could be maximized by using PVA fibers having $\mathrm{OH}^{-}$groups, along with the appropriate in the $\mathrm{Ca}+\mathrm{MB}$ case that supplies the combination of $\mathrm{Ca}^{2+}$ and $\mathrm{CO}_{3}{ }^{2-}$ necessary for self-healing.

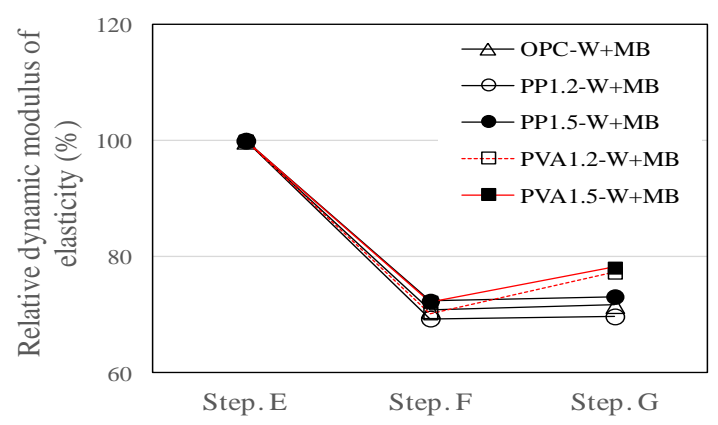

Fig. 9. $\mathrm{W}+\mathrm{MB}$ case.

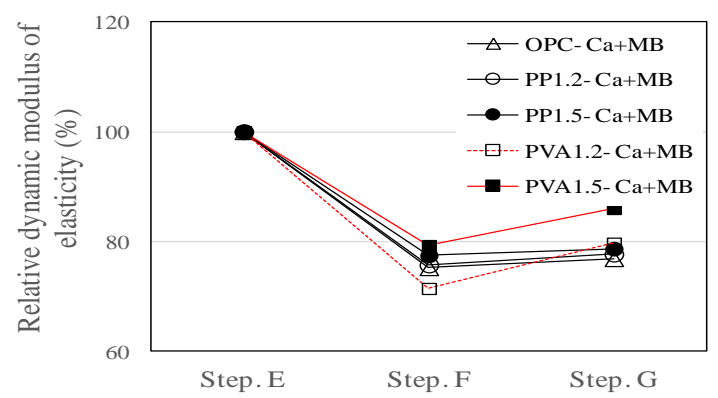

Fig. 10. $\mathrm{Ca}+\mathrm{MB}$ case.

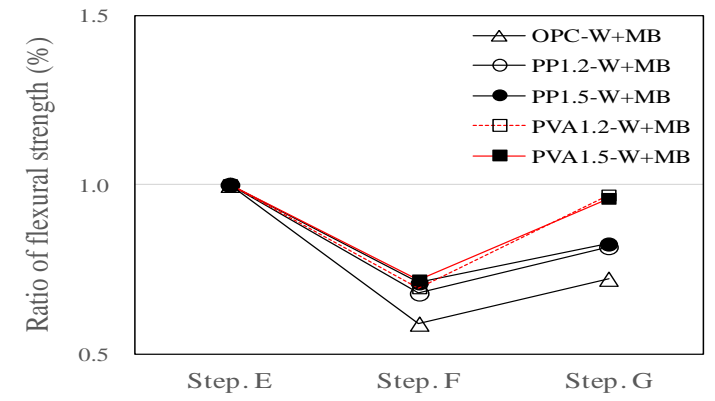

Fig. 11. $W+M B$ case. 


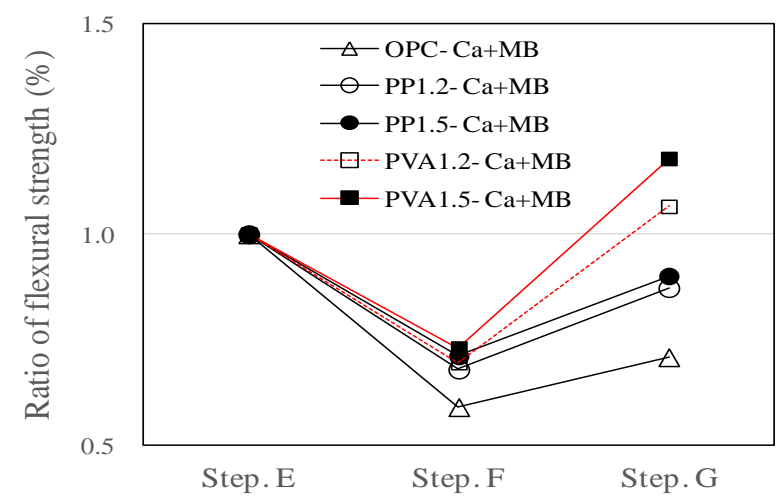

Fig. 12. $\mathrm{Ca}+\mathrm{MB}$ case.

PVA fibers located in the cracked portion of the specimen that had been subjected to freezing and thawing (Step G) were studied using SEM. It was found that the self-healing substance was adhered to the surface of PVA fibers. This observation further confirmed that selfhealing can be effectively promoted by using PVA fibers.

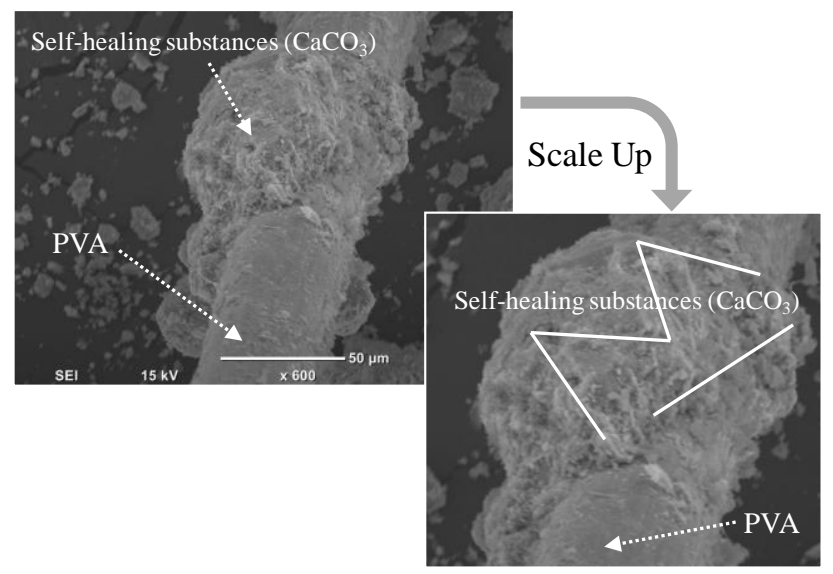

Fig. 13. Surface of a PVA fiber (SEM)

\section{Conclusion}

In this study, we examined cementitious materials that are used to repair and reinforce deteriorated concrete structures and aimed at evaluating the strength recovery of these repaired materials. We were able to suppress the penetration of degradation factors that arise owing to freezing and thawing of these materials. The self-healing process of cracks with a width of $0.1 \mathrm{~mm}$ or more was promoted by effectively dispersing and reducing the occurrence and development of cracks through fiber reinforcement. To that end, the self-healing performance of cracks was determined by evaluating the coefficient of water permeability and the relative dynamic modulus of elasticity and flexural strength. In addition, the nature of the self-healing substance was confirmed by Raman spectroscopic analysis and imaged using SEM. The results of this study are given below.

- Although it is possible to make repairs to cracks resulting from freezing damage using any type of fiber, PVA allowed for a greater recovery than PP. The positive effects of using an aqueous solution of $\mathrm{Ca}(\mathrm{OH})_{2}$ and $\mathrm{CO}_{2}$ micro-bubbles for promoting selfhealing were confirmed.

- In addition to promoting composite self-healing, cementitious repair materials mixed with PVA fibers displayed a good performance in improving concrete strength.

\section{References}

1. Japan Concrete Institute;Practical Guideline for Investigation, Repair and Strengthening of Cracked Concrete Structure; Japan Concrete Institute, Tokyo, Japan, 2013. (In Japanese)

2. Stefan, J.; Effect of cracking and healing on chloride transport in OPC concrete, Cement and Concrete Research, 1996, 26, 6, pp.869.

3. NevilleA.M.; Properties of Concrete, Person Education Limited, USA, 1995.

4. Heesup, C.; Masumi, I.; Sukmin, K.; Hyeonggil, C.; Myungkwan, L.; Effective Crack Control of Concrete by Self-Healing of Cementitious Composites Using Synthetic Fiber, Journal of the Materials,2016, 9, 4, pp.1-14.

5. Stefan, J.; Self-healing of high strength concrete after deterioration by freeze/thaw, Cement and Concrete Research, 1996, 26, 1, pp.55.

6. Edvardsen, C.; Water Permeability and Autogenous Healing of Cracks in Concrete, ACI Materials Journal, 1999, 96, M56, pp.448.

7. Nishiwaki, T.; Koda, M.; Yamada, M.; Mihashi, H.; Kikuta, T.; Experimental study on self-healing capability of FRCC using different types of synthetic fibers, Journal of Advanced Concrete Technology, 2012, 10, pp.195.

8. Heesup, C.; Masumi, I.; Hyeonggil, C.; Myungkwan, L.; Nishiwaki, T.;Shunzo, K.; The fundamental study of the crack control by selfhealing of PVA fiber reinforced cementitious composites, Journal of Civil Engineering and Architecture Research, 2016, 3, 9, pp.1680.

9. Haoliang, H.; Guang, Y.; Self-healing of cracks in cement paste affected by additional $\mathrm{Ca}^{2+}$ ions in the healing agent, Journal of intelligent Material Systems and Structures, 2014, pp.1-12.

10. Hansic, K.; et al.; Fundamental Study on Recycling of Low-quality Recycled Fine Aggregate using Carbonated Nanobubble Water, Proceedings of first international Conference on concrete sustainability, S3-1-4, 2013.

11. Homma, D.; Mihashi, H.; Nishiwaki, T.; Self-healing capability of fiber reinforced cementitious composites, Journal of Advanced Concrete Technology, 2009, 7, 2, pp.217.

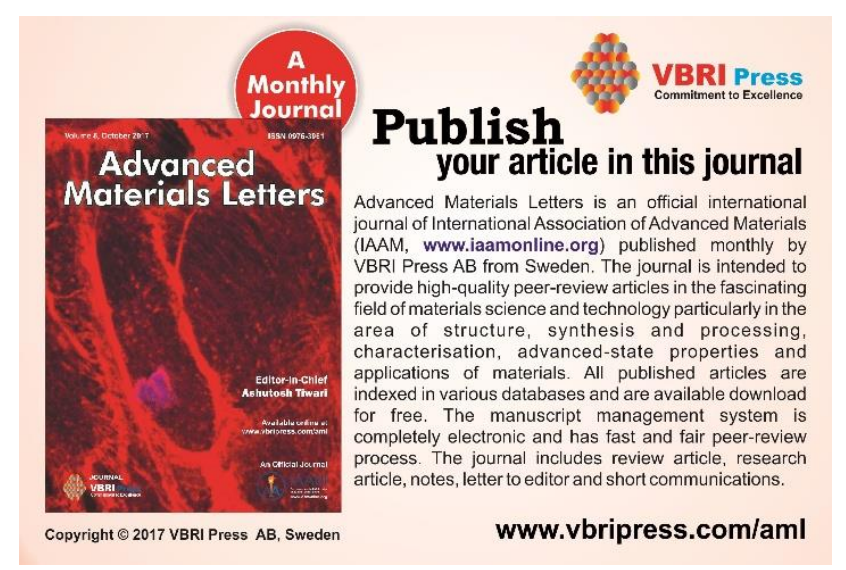

